\title{
Stability and Competitive Equilibrium in Matching Markets with Transfers
}

\author{
JOHN WILLIAM HATFIELD \\ Graduate School of Business, Stanford University \\ and \\ SCOTT DUKE KOMINERS \\ Becker Friedman Institute, University of Chicago
}

This note surveys recent work in generalized matching theory, focusing on trading networks with transferable utility. In trading networks with a finite set of contractual opportunities, the substitutability of agents' preferences is essential for the guaranteed existence of stable outcomes and the correspondence of stable outcomes with competitive equilibria. Closely analogous results hold when venture participation is continuously adjustable, but under a concavity condition on agents' preferences which allows for some types of complementarity.

Categories and Subject Descriptors: J.4 [Computer Applications]: Social and Behavioral Sciences-Economics; K.4.4 [Computers and Society]: Electronic Commerce

General Terms: Economics, Theory

Additional Key Words and Phrases: Matching, Networks, Joint Ventures, Stability, Competitive Equilibrium, Core, Efficiency

\section{INTRODUCTION}

In the half-century since Gale and Shapley [1962] introduced the stable marriage model, matching theory has been extended to encompass successively more general economic settings with relationship-specific utilities. The fundamental solution concept in this literature is stability, the condition that no group of agents can block the match outcome by recontracting. Stable outcomes have been shown to exist in two-sided matching markets - including those for which the matching process determines contractual terms in addition to partnerships - even when agents on both sides of the market may match to multiple agents on the other side. Crucial for these results, however, is a substitutability condition on agents' preferences, which requires that when an agent is presented with new matching opportunities, that agent never desires a previously-rejected opportunity. ${ }^{1}$ The existence results

\footnotetext{
${ }^{1}$ Substituable preferences are sufficient and necessary for the existence of stable outcomes in settings of many-to-one matching (Roth [1984] proved the sufficiency result; Hatfield and Kojima [2008] proved the necessity result), and in settings of many-to-many matching with and without contracts (Roth [1984], Echenique and Oviedo [2006], Klaus and Walzl [2009], and Hatfield and Kominers [2011a] proved sufficiency results; Hatfield and Kojima [2008] and Hatfield and Komin-
}

Authors' addresses: hatfield_john@gsb.stanford.edu, skominers@uchicago.edu

This article describes the results of [Hatfield et al. 2011] and [Hatfield and Kominers 2011b].

The authors appreciate the helpful comments of Fuhito Kojima, Alexandru Nichifor, Michael Ostrovsky, and Alexander Westkamp. 
(along with associated structural characterizations) for two-sided matching models extend to the more general setting of multi-stage, vertical "supply-chain" networks, so long as agents' preferences over the objects being traded are substitutable. ${ }^{2}$

Matching theory now has a number of high-profile applications ${ }^{3}$; hence, it is important to understand the possibilities and limitations of matching theory for market design. In our previous work [Hatfield and Kominers 2012], we showed that supply-chain market structure is essentially necessary for the guaranteed existence of stable outcomes in matching markets without transfers: If a market does not exhibit supply chain structure, then there exists some agent who may both buy from and sell to another agent (perhaps by way of intermediaries); if that agent has additional trading opportunities, then there exist substitutable preferences for all agents such that no stable outcome exists.

The recent work of [Hatfield et al. 2011] and [Hatfield and Kominers 2011b] shows that it is possible to accommodate more general network structures when utility is quasilinear in a transferable numeraire. In such settings, the underlying nature of contractual relationships is important: Substitutability remains essential in trading networks with a finite set of contractual opportunities, while some complementarities may be allowed when venture participation is continuously adjustable.

\section{TRADING NETWORKS WITH BILATERAL CONTRACTS}

The work of [Hatfield et al. 2011] considers contracting over trades - each of which specifies a buyer, a seller, and terms of exchange - and augments the contractual set with transfers of a continuously divisible numeraire over which agents' utilities are assumed to be quasilinear. ${ }^{4}$ In this setting, the choice-theoretic notion of substitutability described above is equivalent to the demand-theoretic substitutability condition that when the prices an agent faces rise, that agent chooses any previously-chosen purchase opportunities for which prices are unchanged and

ers [2011a] proved necessity results). Meanwhile, Hatfield and Milgrom [2005] showed that substitutable preferences are sufficient for the existence of stable outcomes in the setting of many-to-one matching with contracts, but Hatfield and Kojima [2008] showed that there is no corresponding necessity result (see also [Hatfield and Kojima 2010]).

${ }^{2}$ Ostrovsky [2008] and Hatfield and Kominers [2012] showed that substitutable preferences are sufficient to guarantee the existence of stable outcomes; Hatfield and Kominers [2012] proved a corresponding necessity result.

${ }^{3}$ The theory of matching without contracts has been used to design the National Resident Matching Program [Roth and Peranson 1999], the gastroenterology match [Niederle and Roth 2003; 2005; McKinney et al. 2005], and school choice programs in New York [Abdulkadiroğlu et al. 2005; 2009] and Boston [Abdulkadiroğlu et al. 2005]. The theory of matching with contracts has been used to analyze the impact of "branch-of-choice" contracts on cadet-branch matching [Sönmez and Switzer 2011; Sönmez 2011]. In addition, matching with contracts has recently been used as a technical tool for understanding markets with budget-constrained buyers [Hatfield and Milgrom 2005; Ashlagi et al. 2010] (see also [Alaei et al. 2011a; 2011b]), matching markets with regional caps [Kamada and Kojima 2011; 2012], markets with differentiated goods and price controls [Hatfield, Plott, and Tanaka 2011; 2012], and matching with minimal quotas [Fragiadakis et al. 2011].

${ }^{4}$ This model generalizes the models of Crawford and Knoer [1981], Kelso and Crawford [1982], Gul and Stacchetti [1999; 2000], and Sun and Yang [2006; 2009]. 
rejects any previously-rejected sale opportunities for which prices are unchanged. ${ }^{5}$

In this setting, a stable outcome is a set of contracts that is both individually rational (for all agents) and unblocked. In the presence of substitutable preferences, an extension of the [Kelso and Crawford 1982] salary-adjustment process shows that stable outcomes exist in trading networks. Such outcomes are in the core (and, hence, are efficient $)^{6}$; moreover, the set of stable outcomes is essentially equivalent to the set of competitive equilibria. The space of substitutable preferences is the maximal domain over which the existence of stable outcomes may be guaranteedthat is, for any domain of preferences strictly larger than that of substitutability, the existence of competitive equilibria and stable outcomes cannot be guaranteed. ${ }^{7}$

\section{MULTILATERAL CONTRACTING}

Despite the maximal domain results described in Section 2, there are a number of economic settings for which preference substitutabilty is not a valid assumption: automobile manufacturing requires compelementary inputs for production [Fox 2008]; advertising campaigns are coordinated across multiple publishers; information technology firms collaborate on multiparty joint research ventures. In [Hatfield and Kominers 2011b], we introduce a multilateral matching framework which allows us to analyze the aforementioned economic environments. In multilateral matching, sets of two or more agents may enter into contracts over participation in multilateral ventures such as coordinated production or joint research. Certain forms of complementarity can be expressed through multilateral contracts; in particular, the multilateral matching framework embeds a large class of economies with production complementarities.

The maximal domain result of [Hatfield et al. 2011] implies that the existence of stable multilateral contracting outcomes cannot be guaranteed when venture participation is discrete. Nevertheless, stable multilateral contracting outcomes do exist when venture participation is continuously adjustable, so long as agents' preferences are concave in venture participation and there exists a numeraire over which agents' preferences are quasilinear. ${ }^{8}$ Furthermore, stable outcomes correspond to competitive equilibria when agents' utilities are concave. Conversely, and in close analogy with the results of [Hatfield et al. 2011], competitive equilibria induce outcomes

\footnotetext{
${ }^{5}$ Theorem 1 of [Hatfield et al. 2011] shows that this definition of substitutability is equivalent to submodularity of the indirect utility function; this generalizes results of Gul and Stacchetti [1999] and Sun and Yang [2009]. This result also corresponds to an analogous result of Hatfield and Kominers [2012], which shows that in settings without transfers, substitutability is equivalent to quasisubmodularity. Substitutability can also be characterized in terms of $M^{\natural}$-concavity of the utility function; see [Reijnierse et al. 2002; Fujishige and Yang 2003].

${ }^{6}$ By contrast, in settings without transfers, stable outcomes need not be in the core; see [Blair 1988; Echenique and Oviedo 2006]. In the setting of Ostrovsky [2008], Westkamp [2010] characterized the class of network structures for which stable outcomes are guaranteed to be efficient and in the core.

${ }^{7}$ Formally, this means that when one agent's preferences are not substitutable, there exist substitutable preferences for all other agents such that neither stable outcomes nor competitive equilibria exist. (In fact, the substitutable preferences for the other agents can be chosen to have a particularly simple form; see Theorem 8 of [Hatfield et al. 2011].)

${ }^{8}$ The concavity assumption is natural in markets with decreasing returns to scale and scope, but is violated in settings with fixed costs.
} 
that are stable and in the core. Analogues of the first and second welfare theorems hold as well, showing in particular that stable outcomes and competitive equilibria are efficient. We extend the model to allow for cross-contract externalities; even when such externalities are introduced, competitive equilibria exist (although they may not be efficient).

\section{DISCUSSION}

A crucial distinction between the models described in Sections 2 and 3 lies in the conditions on preferences necessary for the main results: substitutability is essential in markets with discrete trades, whereas concavity is essential in markets with continuously adjustable participation levels. Under their respective key conditions, however, these models are surprisingly parallel: ${ }^{9}$ stable outcomes exist, are in the core (and hence are efficient), and correspond to competitive equilibria. We hope that future work will yield insight into these parallels through a deeper understanding of the relationship between substitutability and concavity.

The importance of preference conditions for the guaranteed existence of stable outcomes suggests that market design may be difficult in settings where these conditions are violated. Recent large market results of Kojima et al. [2010], Ashlagi et al. [2011], and Azevedo et al. [2011] suggest that these concerns could be mitigated by sufficient market thickness. For small markets, by contrast, new market design approaches may be needed.

\section{REFERENCES}

AbdulkadiroĞlu, A., Pathak, P. A., And Roth, A. E. 2005. The New York City high school match. American Economic Review 95, 364-367.

AbdulkadiroĞlu, A., Pathak, P. A., And Roth, A. E. 2009. Strategyproofness versus efficiency in matching with indifferences: Redesigning the NYC high school match. American Economic Review 99, 1954-1978.

Abdulkadiročlu, A., Pathak, P. A., Roth, A. E., And Sönmez, T. 2005. The Boston public school match. American Economic Review 95, 368-371.

Alaei, S., Jain, K., And Malekian, A. 2011a. Competitive equilibrium in two sided matching markets with general utility functions. Preprint, arXiv:1006.4696v3.

Alaei, S., Jain, K., And Malekian, A. 2011b. Competitive equilibrium in two sided matching markets with general utility functions. SIGecom Exchanges 10, 2, 34-36.

Ashlagi, I., Braverman, M., And Hassidim, A. 2011. Stability in large matching markets with complementarities. Mimeo, Massachusetts Institute of Technology. (2011 extended abstract, entitled "Matching with couples revisited". In Proceedings of the 12th ACM Conference on Electronic Commerce. 335-336.)

Ashlagi, I., Braverman, M., Hassidim, A., Lavi, R., and Tennenholtz, M. 2010. Position auctions with budgets: Existence and uniqueness. B.E. Journal of Theoretical Economics Advances 10, Article 20.

Ausubel, L. M. 2006. An efficient dynamic auction for heterogeneous commodities. American Economic Review 96, 602-629.

Azevedo, E., Weyl, E. G., And White, A. 2011. Walrasian equilibrium without gross substitutes. Mimeo, University of Chicago.

Blair, C. 1988. The lattice structure of the set of stable matchings with multiple partners. Mathematics of Operations Research 13, 619-628.

\footnotetext{
${ }^{9}$ Similar parallels have been observed in the auction theory literature; see [Ausubel 2006].
}

ACM SIGecom Exchanges, Vol. 10, No. 3, December 2011, Pages 29-34 
Crawford, V. P. And Knoer, E. M. 1981. Job matching with heterogeneous firms and workers. Econometrica 49, 437-450.

EChenique, F. AND Oviedo, J. 2006. A theory of stability in many-to-many matching markets. Theoretical Economics 1, 233-273.

Fox, J. T. 2008. Estimating matching games with transfers. NBER Working Paper 14382.

Fragiadakis, D., Iwasaki, A., Troyan, P., Ueda, S., and Yokoo, M. 2011. Strategy-proof mechanisms for two-sided matching with minimum and maximum quotas. Mimeo, Stanford University.

Fujishige, S. And Yang, Z. 2003. A note on Kelso and Crawford's gross substitutes condition. Mathematics of Operations Research 28, 463-469.

Gale, D. And Shapley, L. S. 1962. College admissions and the stability of marriage. American Mathematical Monthly 69, 9-15.

Gul, F. And Stacchetti, E. 1999. Walrasian equilibrium with gross substitutes. Journal of Economic Theory 87, 95-124.

Gul, F. And Stacchetti, E. 2000. The English auction with differentiated commodities. Journal of Economic Theory 92, 66-95.

Hatfield, J. W. and Kojima, F. 2008. Matching with contracts: Comment. American Economic Review 98, 1189-1194.

Hatfield, J. W. And Kojima, F. 2010. Substitutes and stability for matching with contracts. Journal of Economic Theory 145, 1704-1723.

Hatfield, J. W. And Kominers, S. D. 2011a. Contract design and stability in matching markets. Mimeo, Harvard Business School.

Hatfield, J. W. And Kominers, S. D. 2011b. Multilateral matching. Mimeo, University of Chicago. (2011 extended abstract. In Proceedings of the 12th ACM Conference on Electronic Commerce. 337-338.)

Hatfield, J. W. And Kominers, S. D. 2012. Matching in networks with bilateral contracts. American Economic Journal: Microeconomics. (2010 extended abstract. In Proceedings of the 11th ACM Conference on Electronic Commerce. 119-120.)

Hatfield, J. W., Kominers, S. D., Nichifor, A., Ostrovsky, M., and Westkamp, A. 2011. Stability and competitive equilibrium in trading networks. Mimeo, Stanford University.

Hatfield, J. W. And Milgrom, P. 2005. Matching with contracts. American Economic Review 95, 913-935.

Hatfield, J. W., Plott, C. R., and Tanaka, T. 2011. Price controls, non-price quality competition, and nonexistence of competitive equilibrium. Mimeo, Stanford University.

Hatfield, J. W., Plott, C. R., and Tanaka, T. 2012. Understanding price controls and nonprice competition through matching theory. American Economic Review Papers $\&$ Proceedings.

KAmada, Y. AND KoJIma, F. 2011. Improving efficiency in matching markets with regional caps: The case of the Japan Residency Matching Program. Mimeo, Stanford University.

Kamada, Y. And KoJima, F. 2012. Stability and strategy-proofness for matching with constraints: A problem in the Japanese medical matching and its solution. American Economic Review Papers $\mathcal{G}$ Proceedings.

Kelso, A. S. And Crawford, V. P. 1982. Job matching, coalition formation, and gross substitutes. Econometrica 50, 1483-1504.

Klaus, B. And WalzL, M. 2009. Stable many-to-many matchings with contracts. Journal of Mathematical Economics 45, 422-434.

Kojima, F., Pathak, P. A., And Roth, A. E. 2010. Matching with couples: Stability and incentives in large markets. Mimeo, Harvard Business School.

McKinney, C. N., Niederle, M., And Roth, A. E. 2005. The collapse of a medical labor clearinghouse (and why such failures are rare). American Economic Review 95, 878-889.

Niederle, M. And Roth, A. E. 2003. Unraveling reduces mobility in a labor market: Gastroenterology with and without a centralized match. Journal of Political Economy 111, 1342-1352.

Niederle, M. And Roth, A. E. 2005. The gastroenterology fellowship market: Should there be a match? American Economic Review 95, 372-375. 
Ostrovsky, M. 2008. Stability in supply chain networks. American Economic Review 98, 897923.

Reijnierse, H., van Gellekom, A., And Potters, J. A. M. 2002. Verifying gross substitutability. Economic Theory 20, 767-776.

Roтн, A. E. 1984. Stability and polarization of interests in job matching. Econometrica 52, 47-57.

Roth, A. E. And Peranson, E. 1999. The effects of the change in the NRMP matching algorithm. American Economic Review 89, 748-780.

SÖNMEZ, T. 2011. Bidding for army career specialties: Improving the ROTC branching mechanism. Mimeo, Boston College.

Sönmez, T. And Switzer, T. B. 2011. Matching with (branch-of-choice) contracts at United States Military Academy. Mimeo, Boston College.

Sun, N. AND YANG, Z. 2006. Equilibria and indivisibilities: gross substitutes and complements. Econometrica 74, 1385-1402.

Sun, N. AND YANG, Z. 2009. A double-track adjustment process for discrete markets with substitutes and complements. Econometrica 7\%, 933-952.

Westkamp, A. 2010. Market structure and matching with contracts. Journal of Economic Theory 145, 1724-1738. 